\title{
The fermentation of soluble carbohydrates in rumen contents of cows given diets containing a large proportion of flaked maize
}

\author{
By J. D. SUTTON \\ National Insitute for Research in Dairying, Shinfield, Reading \\ (Received I9 November I968-Accepted 3 February I969)
}

\begin{abstract}
I. Studies were made of the fermentation of D-glucose, D-fructose, D-galactose, D-xylose, $\mathrm{L}$-arabinose and sucrose by rumen contents from two cows fed I $\mathrm{kg}$ hay and 4 or $5 \mathrm{~kg}$ flaked maize once daily. The proportions of volatile fatty acids (VFA) in the rumen before addition of carbohydrates varied widely but on average acetic acid constituted about $52 \%$, propionic acid about $29 \%$ and n-butyric acid about $13 \%$ of the total.

2. In in vitro experiments, $896 \mathrm{mg}$ of the monosaccharides and $85 \mathrm{I} \mathrm{mg} \mathrm{sucrose} \mathrm{were} \mathrm{added}$ to $150 \mathrm{~g}$ mixed rumen contents incubated for $2 \mathrm{~h}$; the carbohydrates were added at $10 \mathrm{~min}$ intervals throughout the incubation on three occasions with each cow. Mean proportions of the carbohydrates fermented ranged from about $60 \%$ of the pentoses to about $85 \%$ of sucrose and glucose. Of the VFA produced from galactose and the pentoses, acetic acid constituted about $40 \%$, propionic acid $45-55 \%$ and $n$-butyric acid $\mathrm{I}-7 \%$; very little n-valeric acid was produced. With the other carbohydrates results from the two cows differed, owing mainly to the production of appreciable amounts of n-valeric acid with one cow only. Acetic acid constituted about $40 \%$ of the VFA produced from fructose and sucrose, propionic acid $20-40 \%$, n-butyric acid $14-22 \%$ and n-valeric acid up to $12 \%$. The proportions of VFA produced from glucose were intermediate between the other two groups.

3. Net recovery of carbon from fermented carbohydrate in VFA was about $35-45 \%$. A further $\mathrm{I}-6 \%$ of fermented glucose, fructose and sucrose was recovered in lactic acid.

4. In in vivo experiments, the monosaccharides only were infused into the rumen for $8 \mathrm{~h}$ at the rate of $200 \mathrm{~g} / \mathrm{h}$. Changes in the concentrations of substrates and products varied widely, owing to the variable basal fermentation, but changes in the proportions of VFA in the rumen were similar to those found in vitro.

5. The results of the in vitro experiments were compared with those obtained in earlier experiments in which the same cows were given a diet containing $70 \%$ hay. Significant regressions $(P<0.05)$ were found between the molar proportions of acetic, propionic and $\mathbf{n}$-valeric acids produced from the substrates and the proportions of these acids present in the rumen contents at the start of the incubations, but the relationships differed markedly among the different carbohydrates. Most of the significant regressions were positive but negative regressions for propionic acid production from fructose and sucrose with one cow suggested the existence of more complex interrelationships among two or more VFA.
\end{abstract}

In a previous paper, Sutton (I968) reported clear differences in the fermentation of six soluble carbohydrates when they were added to rumen contents from two cows given a diet containing a large proportion of hay. There is evidence (Eusebio, Shaw, Leffel, Lakshmanan \& Doetsch, 1959; Baldwin, Wood, \& Emery r963; Wallnöfer, Baldwin \& Stagno, 1966) that the products of fermentation of glucose vary according to the nature of the diet fed to the cow. Baldwin \& Palmquist (1965) found quite a different pattern of enzymes in the rumen when cows were given chopped barley straw or a concentrate mixture; many experiments have shown variations in bacterial and protozoal populations between different diets (see Hungate, 1966).

The purpose of the present experiments was to examine the fermentation of the same six carbohydrates studied previously, but on this occasion the cows were given 
diets designed to produce a completely different basal fermentation. The diets chosen contained only about $17-20 \%$ hay compared with $70 \%$ in the previous experiment. The results have shown that the products of fermentation of soluble carbohydrates do vary according to the nature of the basal fermentation, but that the extent of the changes varies with different carbohydrates.

\section{EXPERIMENTAL}

\section{Animals and management}

Two dry Friesian cows, Adelaide and Desmine, each fitted with a permanent rumen fistula closed with a rubber cannula and bung (Balch \& Cowie, 1962) were used in all the experiments. They were the same cows as were used in the earlier work and were

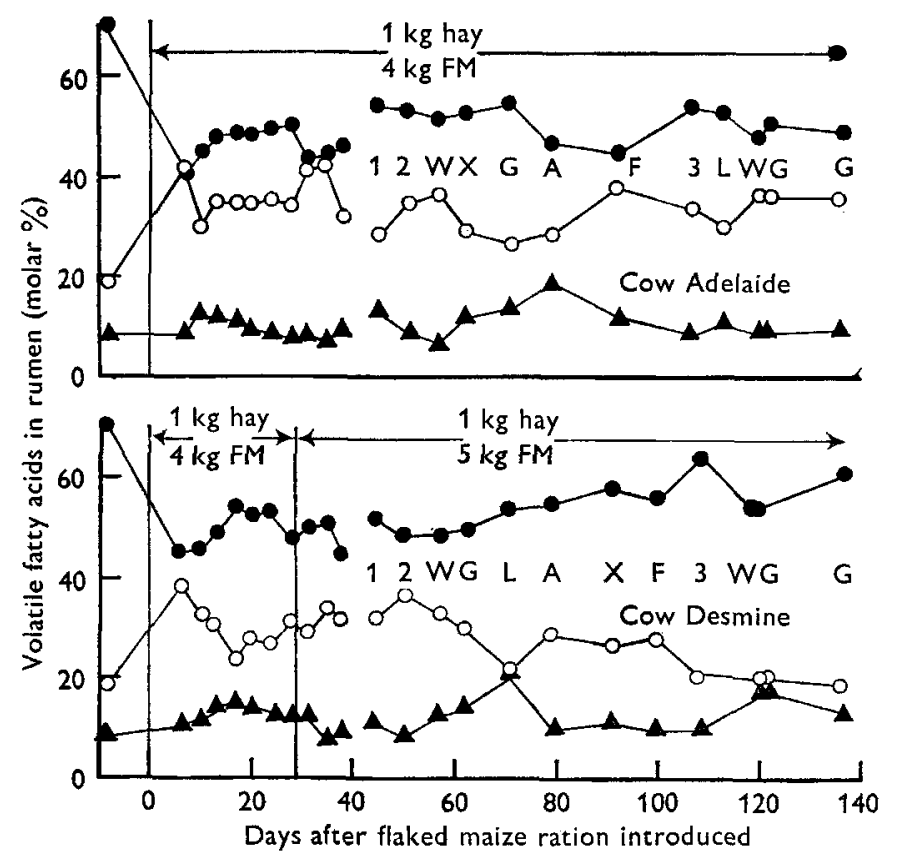

Fig. I. Molar proportions of acetic (O), propionic $(O)$ and $n$-butyric $(\Delta)$ acids in the rumen of both cows when they were changed from the hay diet to the flaked maize (FM) diet. Samples up to 38 days after the change of diet were taken $23 \mathrm{~h}$ after feeding; all later samples were taken $14 \mathrm{~h}$ after feeding. Also shown are the days for in vitro incubations $(I, 2,3)$ and for in vivo infusion of glucose $(G)$, fructose $(F)$, galactose $(L)$, xylose $(X)$, arabinose $(A)$ and water $(W)$.

housed in metabolism stalls. Over a period of I week their daily ration was changed from $4^{\circ} \circ \mathrm{kg}$ hay and $\mathrm{r} \cdot 6 \mathrm{~kg}$ dairy cubes to $\mathrm{I} \cdot 0 \mathrm{~kg}$ hay and $4^{\circ} \circ \mathrm{kg}$ flaked maize. Rumen samples were taken at intervals during the next 4 weeks. The molar proportions of the volatile fatty acids (VFA) changed markedly in both cows following the change of ration but considerable differences existed between the cows after 4 weeks (Fig. I). In an attempt to induce similar proportions of VFA in the two cows, the amount of flaked maize fed to Desmine was increased to $5 \mathrm{~kg}$. No change was made in the ration 
of Adelaide. Within I week the proportions of VFA in the two cows had become quite similar and the experiments were therefore begun. Despite these initial attempts to obtain similar and stable fermentations, wide fluctuations occurred in the proportions of VFA in the rumen contents of the two cows during the succeeding weeks of the experiments (Fig. I).

Feeds were offered once daily at $17.00 \mathrm{~h}$ and were always completely consumed within 3 h. Each cow received $5 \circ \mathrm{g}$ vitamin $A$ and D supplement (Beta no. $3 ; \mathrm{V}$. W. Eves and Co. Ltd, Hainault, Essex) and $5 \circ \mathrm{g}$ mineral mix (Churn Cattle Mineral Mix; British Glues and Chemicals Ltd, London, WCr) daily. Commercial salt licks providing a wide range of minerals (Mineral Salt Licks; Bell and Son Ltd, Liverpool) were available throughout. At all times, except during experimental infusions, drinking water was available and, in addition, water was infused into the rumen by gravity flow at 68 1./day.

\section{In vitro experiments}

The carbohydrates added were D-glucose, D-fructose, D-galactose, D-xylose, $\mathrm{L}$-arabinose and sucrose; they were from the same batches as in the previous experiments (Sutton, I968).

On each occasion, the incubations were conducted in fourteen $250 \mathrm{ml}$ round flasks each fitted with a bunsen valve and a syringe. The incubating medium was $15 \circ \mathrm{g}$ mixed rumen contents removed from the rumen about $\mathrm{I} 4 \mathrm{~h}$ after the evening feed. The mean dry-matter percentage in the rumen contents of Desmine was $6.0 \%$ and of Adelaide only $3.0 \%$. Therefore in preparing the incubating medium, $120 \mathrm{ml}$ fluid and $30 \mathrm{~g}$ solids were used for Desmine but for Adelaide, as the contents were so fluid, no attempt was made to separate and reconstitute the contents and $150 \mathrm{ml}$ mixed contents were measured out directly. The resulting mean dry-matter percentage of the incubating media was $6.6 \%$ for Desmine and $3.2 \%$ for Adelaide.

The rate of addition of carbohydrate in vitro was matched to the rate of infusion in vivo; in these and the previous experiments, carbohydrates were infused in vivo at $200 \mathrm{~g} / \mathrm{h}$, but since the mean weight of rumen contents on the flaked maize diet $(67 \mathrm{~kg})$ was considerably lower than when the hay diet was given, the rate of infusion per unit weight of rumen contents was greater. The amount of carbohydrate added during the $2 \mathrm{~h}$ incubation in vitro was therefore increased from $750 \mathrm{mg}$ ( $713 \mathrm{mg}$ sucrose) to $896 \mathrm{mg}$ ( $85 \mathrm{I} \mathrm{mg}$ sucrose). The carbohydrates were added on the basis of equal g-atoms of carbon; the weight of sucrose was, accordingly, less than the weight of the other carbohydrates.

Incubations were conducted on three occasions with digesta from each cow. On each occasion, each carbohydrate, dissolved in artificial saliva (McDougall, I948), was added at $10 \mathrm{~min}$ intervals to duplicate flasks throughout the $2 \mathrm{~h}$ incubation. Two flasks were removed at the start of each incubation; artificial saliva alone was added to two further flasks (control) throughout the incubation. The flasks were shaken at IIO strokes/min in a water bath at $39^{\circ}$. At the end of $2 \mathrm{~h}$, the fermentation was stopped and samples were taken for analysis. Further details of the procedures have been given previously (Sutton, 1968).

Calculations. The results were calculated in a way similar to those for the previous 
experiments but with the following modifications. Calculation of the amounts of acids produced indicated that negative production, or net utilization, of small amounts of isobutyric and isovaleric acids had occurred in occasional flasks. This result appeared to be due to the errors attached to analysing for the small concentrations of these acids present in the rumen contents. To overcome the resulting difficulties in calculating molar proportions of VFA produced, the mean amount of the two acids produced in all the flasks for any occasion was calculated and results were then re-calculated on the assumption that the gross production of the two acids was the same in all the flasks. Since the gross production of other VFA varied considerably among substrates, the molar percentage of the branched-chain acids produced varied even though the amount produced was assumed to be constant. On some occasions n-valeric acid was produced in large amounts and there were no grounds for excluding its production from the calculations, as had been done in the earlier experiments.

Results are reported in terms of both net and gross production of VFA. Gross production is the total amount of VFA produced during the incubation. Net production is the same value less the amount of VFA produced in the control flasks. Although absolute values differed according to whether they were based on net or gross production, the relative differences among carbohydrates did not differ greatly whichever basis was used for comparison. In order to simplify discussion, results are generally considered in terms of net production except when a comparison between the two sets of values is being made.

Statistical analyses. Substrate means are presented for each of the two cows and each mean is an average of six observations representing duplicate incubations on three occasions with each cow. As in the previous experiments the standard error of a difference between substrate means of a given cow was derived from the interaction between substrates and occasions. Similarly, when substrate values averaged over both animals were considered, the error was derived from the pooled estimate of the interaction between substrates and occasions within cows. Combined analysis of variance for both cows produced evidence with certain variates of significant interaction between substrates and cows; these cases are mentioned later in the text. However, this interaction has not been used as an error basis for drawing conclusions about substrate differences in a general population because the sample of cows was deemed inadequate. Consequently the conclusions refer to only the two animals involved, although a much wider validity may well apply.

\section{In vivo experiments}

The same five monosaccharides incubated in vitro were infused in vivo; sucrose was not infused. All were infused into the rumen at $200 \mathrm{~g} / \mathrm{h}$ in aqueous solution $(100 \mathrm{~g} / \mathrm{l}$.) for $8 \mathrm{~h}$. The infusions began $\mathrm{I}_{4} \mathrm{~h}$ after the evening feed. The site of infusion was about $7 \mathrm{~cm}$ below the surface of the rumen contents below the rumen fistula. Samples were taken before (o), and $2,4,6$ and $8 \mathrm{~h}$ after the start of infusion. They were aspirated from the bottom of the ventral sac and from the reticulum; equal volumes from the two sites were mixed and the $\mathrm{pH}$ was measured. Samples were then stored for analysis. At least 8 days were allowed to elapse between infusions to reduce carry-over 
effects except after a control infusion of water. Water was infused twice and glucose three times into each cow. The other monosaccharides were infused once only into each cow.

Further details of the procedures have been given previously (Sutton, I968).

\section{Analytical procedures}

Samples were analysed for the concentrations of total VFA by steam distillation, of lactic acid by the procedure of Elsden \& Gibson (1954), of carbohydrates as total reducing substances (TRS) and of starch by the strength of the iodophilic reaction. Molar proportions of VFA were determined by gas chromatography. Further details have been given by Sutton (1968).

\section{RESULTS}

The variability of the basal fermentation as reflected in the proportions of VFA in the rumen is illustrated in Fig. I. Such variability is found frequently when diets containing a large proportion of cereals are given (J. D. Sutton, unpublished). The occasions on which in vitro incubations or in vivo infusions were made are indicated in Fig. I.

\section{In vitro experiments}

The conditions in the rumen at the start of each incubation are shown in Table $\mathrm{I}$. Fermentation of carbohydrates. None of the carbohydrates was completely fermented

Table I. In vitro: $p H$, concentration and molar proportions of volatile fatty acids $(V F A)$ and concentration of lactic acid in rumen contents of both cows at the start of each incubation

\begin{tabular}{|c|c|c|c|c|c|c|c|c|c|}
\hline \multirow[b]{2}{*}{ Incubation } & \multirow[b]{2}{*}{$\mathrm{pH}$} & \multirow[b]{2}{*}{$\begin{array}{c}\text { VFA } \\
(m-\text { moles } / 1 .)\end{array}$} & \multirow{3}{*}{$\begin{array}{l}\text { Lactic acid } \\
(\mathrm{m}-\mathrm{moles} / 1 .)\end{array}$} & \multicolumn{6}{|c|}{ Molar \% } \\
\hline & & & & Acetic & Propionic & Isobutyric & n-Butyric & Isovaleric & $\mathrm{n}$-Valeric \\
\hline \multicolumn{9}{|c|}{ Cow Adelaide } & \\
\hline $\mathbf{I}$ & $6 \cdot 40$ & $58 \cdot 4$ & 0 & $54 \cdot 7$ & $28-6$ & $\mathbf{1} \cdot 8$ & $13 \cdot 3$ & 0.9 & 0.7 \\
\hline 2 & $6 \cdot 50$ & $56 \cdot 4$ & $\circ$ & $53 \cdot 5$ & $35 \cdot 3$ & 0.8 & $8 \cdot 9$ & 0.9 & 0.6 \\
\hline 3 & $6 \cdot 45$ & $54 \cdot 6$ & 0.14 & $54 \cdot I$ & $34 \cdot 2$ & 0.9 & 8.9 & $1 \cdot 0$ & 0.9 \\
\hline \multicolumn{10}{|c|}{ Cow Desmine } \\
\hline I & $6 \cdot 58$ & $72 \cdot 9$ & 0.13 & $52 \cdot I$ & $32 \cdot 5$ & $x \cdot I$ & $\mathrm{II} \cdot 2$ & 0.6 & 2.5 \\
\hline 2 & 6.23 & $76 \cdot 7$ & $\circ$ & $48 \cdot 8$ & $3^{6 \cdot 9}$ & 0.9 & $8 \cdot 4$ & 0.9 & $4 \cdot I$ \\
\hline 3 & $6 \cdot 74$ & 63.3 & 0.42 & $63 \cdot 5$ & $2 I \cdot 2$ & $1 \cdot 4$ & $10 \cdot 2$ & $2 \cdot 5$ & $\mathrm{I} \cdot 2$ \\
\hline
\end{tabular}

(Table 2). They can be divided into three groups, in decreasing order of the proportions fermented: sucrose and glucose; fructose and galactose; and xylose and arabinose. These groups were not clearly defined and only the more extreme differences were significant $(P<0.05)$. The mean proportions fermented by Adelaide were significantly less $(P<0.005)$ than those fermented by Desmine. This difference may be related to the smaller proportion of dry matter in the rumen contents of Adelaide. The importance of the proportion of solid material in stimulating the fermentation 
of glucose in vitro has been reported elsewhere (Phillipson \& McAnally, 1942; Sutton, 1968).

Total VFA and lactic acid. Gross and net amounts of total VFA produced (Tables 3 and 4) were approximately related to the amounts of carbohydrate fermented. Lactic acid was produced only from sucrose, glucose and fructose, apart from traces produced on one occasion from galactose and xylose (Table 4). The significance of differences among the carbohydrates in the amounts of VFA and lactic acid produced was not

Table 2. In vitro: mean percentage of each carbohydrate fermented by rumen contents

(During the $2 \mathrm{~h}$ incubation $85 \mathrm{I} \mathrm{mg}$ sucrose and $896 \mathrm{mg}$ of the other carbohydrates were added. Further details of the incubation procedures are given on p. 569. The least significant difference (LSD) $(P=0.05)$ among substrates is given)

\begin{tabular}{|c|c|c|}
\hline \multirow[b]{2}{*}{ Substrate } & \multicolumn{2}{|c|}{ Carbohydrate fermented $(\%)$} \\
\hline & $\begin{array}{c}\text { Cow } \\
\text { Adelaide }\end{array}$ & $\begin{array}{c}\text { Cow } \\
\text { Desmine }\end{array}$ \\
\hline Sucrose & $84 \cdot 9$ & $92 \cdot 0$ \\
\hline Glucose & $77 \cdot 9$ & $93^{\circ} 9$ \\
\hline Fructose & 64.0 & $82 \cdot 2$ \\
\hline Galactose & $59 \cdot 8$ & $80 \cdot I$ \\
\hline Xylose & 50.0 & 65.9 \\
\hline Arabinose & 54.0 & 73.7 \\
\hline $5 \%$ LSD & 14.7 & 10.0 \\
\hline
\end{tabular}

Table 3. In vitro: mean gross production of volatile fatty acids (VFA) and starch and molar proportions of VFA produced

(During the $2 \mathrm{~h}$ incubation $85 \mathrm{I} \mathrm{mg}$ sucrose and $896 \mathrm{mg}$ of the other carbohydrates were added Further details of the incubation procedures are given on p. 569. The least significant difference (LSD) $(P=0.05)$ among substrates is given)

\begin{tabular}{|c|c|c|c|c|c|c|c|}
\hline \multirow[b]{2}{*}{ Substrate } & \multirow[b]{2}{*}{ Starch* } & \multirow[b]{2}{*}{$\begin{array}{c}\text { VFA } \\
\text { (m-moles) }\end{array}$} & \multicolumn{5}{|c|}{ Molar \% } \\
\hline & & & Acetic & Propionic & n-Butyric & n-Valeric & $\begin{array}{c}\text { Isobutyric } \\
+ \\
\text { isovaleric }\end{array}$ \\
\hline \multicolumn{8}{|c|}{ Cow Adelaide } \\
\hline Sucrose & $I \cdot 0$ & 5.04 & $46 \cdot 9$ & $36 \cdot 9$ & 13.7 & $1 \cdot 5$ & $1 \cdot 0$ \\
\hline Glucose & $I \cdot 0$ & $4 \cdot 97$ & $44 \cdot 7$ & $4 I \cdot I$ & $12 \cdot 1$ & $\mathbf{I} \cdot \mathbf{O}$ & $\mathbf{I} \cdot \mathbf{I}$ \\
\hline Fructose & 0.3 & $3 \cdot 82$ & $48 \cdot 4$ & $32 \cdot 9$ & $16 \cdot 2$ & $\mathbf{I} \cdot \mathbf{I}$ & $r \cdot 4$ \\
\hline Galactose & 0.3 & $4 \cdot 34$ & $46 \cdot 8$ & $45 \cdot 4$ & $5 \cdot 9$ & 0.7 & $x \cdot 2$ \\
\hline Xylose & $\circ$ & 3.75 & $49 \cdot 2$ & $42 \cdot 5$ & $5 \cdot 9$ & I.O & $1 \cdot 4$ \\
\hline Arabinose & 0.2 & $3 \cdot 80$ & $49 \cdot 7$ & $42 \cdot 9$ & $5 \cdot 2$ & 0.8 & $1-4$ \\
\hline Control & $\circ$ & I.25 & $62 \cdot 1$ & $16 \cdot 6$ & $13 \cdot 3$ & $3 \cdot 2$ & $4 \cdot 8$ \\
\hline $5 \%$ LSD & - & - & $6 \cdot 6$ & $8 \cdot 8$ & $6 \cdot 0$ & $I \cdot 6$ & 一 \\
\hline \multicolumn{8}{|c|}{ Cow Desmine } \\
\hline Sucrose & $1 \cdot 2$ & $5 \cdot 34$ & $5 \mathrm{I} \cdot 7$ & $23 \cdot 3$ & $15 \cdot 2$ & $8 \cdot I$ & $I \cdot 7$ \\
\hline Glucose & $I \cdot 3$ & 6.05 & $44^{\prime} 9$ & 35.4 & I $2 \cdot 3$ & $5 \cdot 9$ & $I \cdot 5$ \\
\hline Fructoset & 0.8 & $5 \cdot 14$ & $48 \cdot 5$ & $23 \cdot 6$ & $16 \cdot 9$ & $8 \cdot 5$ & $\mathbf{I} \cdot 8$ \\
\hline Galactose & 0.7 & $5 \cdot 89$ & $48 \cdot 6$ & $40 \cdot 6$ & $7 \cdot 5$ & $\mathrm{I} \cdot 8$ & $x \cdot 5$ \\
\hline Xylose & 0.3 & 5.03 & $46 \cdot 6$ & $44^{\prime} I$ & $5 \cdot 4$ & $2 \cdot 2$ & $\mathbf{r} 7$ \\
\hline Arabinose & 0.5 & $5 \cdot 61$ & $46 \cdot 8$ & $44 \cdot 5$ & $5^{\circ} \circ$ & $2 \cdot 0$ & $\mathbf{I} 7$ \\
\hline Control & 0 & $2 \cdot 19$ & $57 \cdot 3$ & $27 \cdot 5$ & $8 \cdot 4$ & $2 \cdot 1$ & $4 \% 7$ \\
\hline $5 \%$ LSD & - & - & $4 \cdot 5$ & $12 \cdot 1$ & $5 \cdot 3$ & $4^{\cdot 6}$ & - \\
\hline
\end{tabular}

* Determined by eye on a scale $0-3$ from the iodophilic reaction.

$\uparrow$ In addition to the acids shown, n-caproic acid formed $0.7 \%$ of the VFA produced. 
calculated as they were of limited value in view of the wide differences in the amount of substrate fermented. The efficiency of conversion of fermented carbohydrate into these products was deemed to be more meaningful and is presented later.

Proportions of $V F A$. The carbohydrates produced similar proportions of acetic acid but quite different proportions of the other VFA (Tables 3 and 4 ) and they can be divided into three groups on this basis. Galactose, xylose and arabinose did not differ significantly in the proportions of any VFA produced when the results from both cows were combined although some differences just reached significance $(P<0.05)$

Table 4. In vitro: mean net production of volatile fatty acids (VFA) and lactic acid and molar proportions of VFA produced

(During the $2 \mathrm{~h}$ incubation $85 \mathrm{Img}$ sucrose and $896 \mathrm{mg}$ of the other carbohydrates were added. Further details of the incubation procedures are given on p. 569. The least significant difference (LSD) $(P=0.05)$ among substrates is given)

\begin{tabular}{|c|c|c|c|c|c|c|}
\hline \multirow[b]{2}{*}{ Substrate } & \multirow[b]{2}{*}{$\begin{array}{c}\text { VFA } \\
\text { (m-moles) }\end{array}$} & \multirow[b]{2}{*}{$\begin{array}{l}\text { Lactic acid } \\
\text { (m-moles) }\end{array}$} & \multicolumn{4}{|c|}{ Molar \% } \\
\hline & & & Acetic & Propionic & n-Butyric & $\mathrm{n}$-Valeric \\
\hline \multicolumn{7}{|c|}{ Cow Adelaide } \\
\hline Sucrose & 3779 & 0.49 & $42 \cdot 1$ & $42 \cdot 9$ & $14 \cdot I$ & 0.9 \\
\hline Glucose & $3 \cdot 72$ & 0.29 & $39 \cdot 3$ & $48 \cdot 5$ & $12 \cdot 1$ & $0 \cdot 1$ \\
\hline Fructose & $2 \cdot 57$ & 0.51 & $41 \cdot 8$ & 40.1 & $18 \cdot 2$ & $-0 \cdot 1$ \\
\hline Galactose & 3.09 & 0 & $4 I \cdot 5$ & $56 \cdot 3$ & $2 \cdot 8$ & -0.6 \\
\hline Xylose & $2 \cdot 50$ & 0 & $43 \cdot 3$ & $54 \cdot 8$ & $2 \cdot I$ & -0.2 \\
\hline Arabinose & $2 \cdot 55$ & $\circ$ & $44^{\circ} I$ & $55^{\prime 2}$ & $\mathbf{I} \cdot \mathbf{I}$ & -0.4 \\
\hline $5 \% \mathrm{LSD}$ & - & - & $5 \cdot 8$ & $7 \cdot 4$ & 10.5 & $\mathrm{I} \cdot \mathbf{8}$ \\
\hline \multicolumn{7}{|c|}{ Cow Desmine } \\
\hline Sucrose & & 0.21 & $48 \cdot 3$ & $2 I \cdot 6$ & $18 \cdot 5$ & II $\cdot 6$ \\
\hline Glucose & 3.87 & 0.10 & $39^{\circ} 0$ & $3^{8 \cdot 9}$ & $14 \cdot \mathrm{I}$ & $8 \cdot 0$ \\
\hline Fructose* & $2 \cdot 95$ & $0: 30$ & $42 \cdot 6$ & $21 \cdot 7$ & $22 \cdot 2$ & $12 \cdot 6$ \\
\hline Galactose & $3 \cdot 70$ & 0 & 44.7 & $45 \cdot 7$ & $7 \cdot 2$ & $2 \cdot 4$ \\
\hline Xylose & $2 \cdot 84$ & 0 & $39 \cdot 2$ & $55^{\circ} \circ$ & $2 \cdot 8$ & $3 \cdot 0$ \\
\hline Arabinose & 3.42 & 0 & $40 \cdot 2$ & $54 \cdot 8$ & $2 \cdot 4$ & $2 \cdot 6$ \\
\hline $5 \%$ LSD & - & - & $4 \cdot 6$ & 16.7 & $7 \cdot 2$ & $7 \cdot 1$ \\
\hline
\end{tabular}

* In addition to the acids shown, n-caproic acid formed $0.7 \%$ of the VFA produced.

for individual cows. They were characterized by producing large proportions of propionic acid and very small proportions of $n$-butyric and n-valeric acids. Fructose and sucrose constituted a second group; no significant differences were detected between them in the proportions of VFA produced when results for both cows were combined although one difference reached significance $(P<0.05)$ for Desmine. They produced relatively large proportions of $n$-butyric acid and, in Desmine, $n$-valeric acid, and small proportions of propionic acid. Glucose was intermediate between the two other groups. The significance of differences between glucose and the other two groups varied between cows and between net and gross production. However, if results from both cows are averaged, glucose differed significantly $(P<0.05)$ from sucrose in producing a smaller proportion of acetic acid and a greater proportion of propionic acid, from fructose in producing a greater proportion of propionic acid and a smaller proportion of $n$-butyric acid, and from galactose, xylose and arabinose in producing a greater proportion of n-butyric acid. 
The cows differed markedly in the proportions of VFA produced from the substrates. The cow $\times$ substrate interaction was significant for the proportion of propionic and $n$-valeric acids produced on both a gross $(P<0.025)$ and a net $(P<0.1)$ basis. This was associated with the production of a much greater proportion of $n$-valeric acid from all the substrates, especially sucrose, fructose and glucose, with Desmine than with Adelaide, the difference between cows being significant $(P<0.005)$. The significance of the cow $\times$ substrate interaction for propionic acid was due mainly to the production of a smaller proportion of that acid from fructose and sucrose in Desmine than in Adelaide; the mean difference between cows was significant $(P<0.005)$ for net but not gross production of propionic acid.

Table 5. In vitro: mean percentage net and gross recovery of carbohydrate carbon in volatile fatty acids $(V F A)$ and lactic acid

(During the $2 \mathrm{~h}$ incubation $85 \mathrm{I} \mathrm{mg}$ sucrose and $896 \mathrm{mg}$ of the other carbohydrates were added. Further details of the incubation procedures are given on p. 569. The least significant difference (LSD) $(P=0.05)$ among substrates is given)

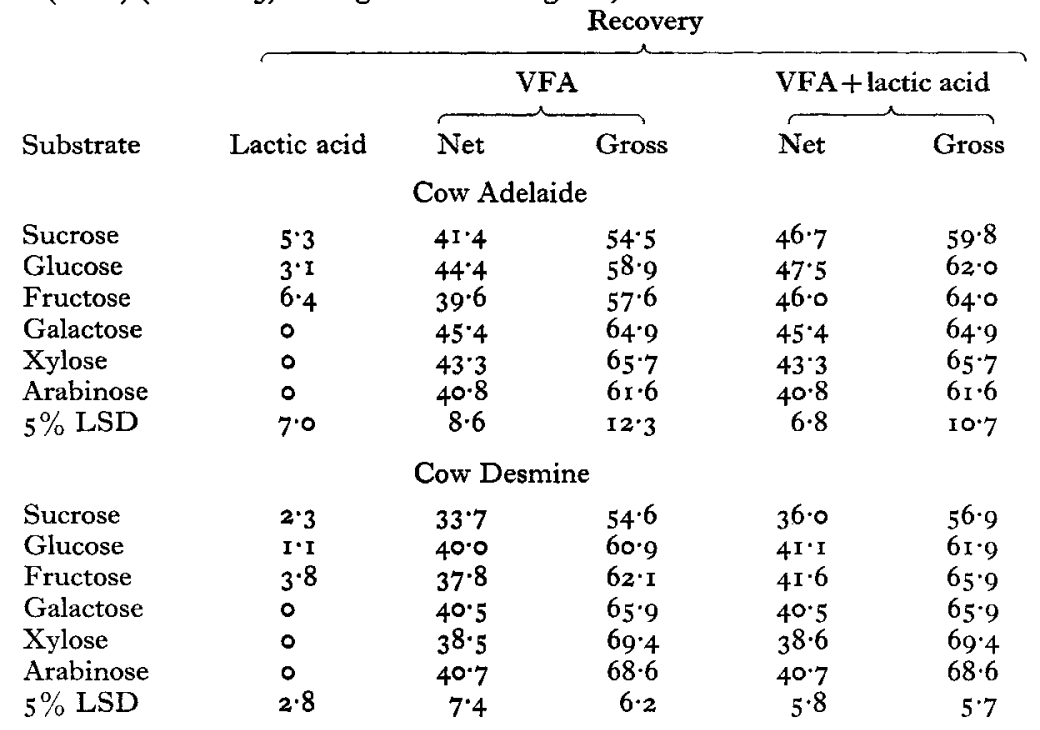

Starch. Estimation of the amounts of iodophilic substance produced was imprecise and results were confused by the variable amount found in the rumen contents at the start of the different incubations. However, there was a distinct tendency for more to be produced from glucose and sucrose than from any of the other carbohydrates (Table 3). The amounts of iodophilic substance produced were related to the amount of carbohydrate metabolized.

Recovery of fermented carbohydrate. The recovery of VFA and lactic acid in carbon from fermented carbohydrate (Table 5) was calculated from both the net and the gross production results as described previously (Sutton, I968). Net recovery in VFA and in VFA plus lactic acid averaged about $40 \%$ and no differences between substrate means were significant although there was a highly significant difference $(P<0.005)$ between cows. The mean proportion of carbohydrate recovered in lactic acid was 
relatively small, forming a maximum of only $16 \%$ of the total carbon recovered. However, the proportion varied widely between occasions as well as between substrates and on one occasion $46 \%$ of the carbon recovered from fructose was in lactic acid.

\section{In vivo experiments}

As in the in vitro experiments, the proportions of VFA in the rumen at the start of the infusions varied widely (Table 6 and Fig. I). The effect was more serious than in the in vitro experiments as only one substrate could be studied on any one occasion

Table 6. In vivo: concentration and molar proportions of volatile fatty acids $(V F A)$ and $p H$ in the rumen of both cows before the start of infusions

\begin{tabular}{|c|c|c|c|c|c|c|c|c|}
\hline & & & & & Mo & & & \\
\hline & $\mathrm{pH}$ & $\begin{array}{c}\text { VFA } \\
(\mathrm{m}-\mathrm{moles} / 1 .)\end{array}$ & Acetic & Propionic & Isobutyric & n-Butyric & Isovaleric & n-Valeric \\
\hline & & & & N Adelaide & & & & \\
\hline $\begin{array}{l}\text { Mean } \\
\text { Range }\end{array}$ & $\begin{array}{c}6 \cdot 57 \\
6 \cdot 35^{-6 \cdot 95}\end{array}$ & $\begin{array}{c}65 \cdot 4 \\
63 \cdot 6-69 \cdot 5\end{array}$ & $\begin{array}{c}50 \cdot 3 \\
45 \cdot 3-54 \cdot 7\end{array}$ & $\begin{array}{c}33 \cdot 3 \\
26 \cdot 8-38 \cdot 1\end{array}$ & $\begin{array}{c}I \cdot I \\
0 \cdot 7-I \cdot 6\end{array}$ & $\begin{array}{c}\text { II'3 } \\
7 \cdot 0-19 \cdot 1\end{array}$ & $\begin{array}{c}2 \cdot 0 \\
0.9-2 \cdot 7\end{array}$ & $\begin{array}{c}2 \cdot 0 \\
0.6-4 \cdot 2\end{array}$ \\
\hline & & & & N Desmine & & & & \\
\hline $\begin{array}{l}\text { Mean } \\
\text { Range }\end{array}$ & $\begin{array}{c}6 \cdot 66 \\
6 \cdot 30-7 \cdot 10\end{array}$ & $\begin{array}{c}59 \cdot 5 \\
51 \cdot 7-66 \cdot 9\end{array}$ & $\begin{array}{c}54 \cdot 8 \\
49 \cdot 2-60 \cdot 9\end{array}$ & $\begin{array}{c}25.1 \\
18.8-32 \cdot 8\end{array}$ & $\begin{array}{c}1 \cdot 4 \\
0.8-1 \cdot 9\end{array}$ & $\begin{array}{c}14.0 \\
10.2-19.7\end{array}$ & $\begin{array}{c}2 \cdot 3 \\
0 \cdot 9-4 \cdot 7\end{array}$ & $\begin{array}{c}2 \cdot 4 \\
I \cdot 3-4 \cdot I\end{array}$ \\
\hline
\end{tabular}

Table 7. In vivo: difference between rumen samples, taken at the start and after $8 h$ of infusion, in $p H$ and in concentrations of volatile fatty acids (VFA), lactic acid, total reducing substances (TRS) and starch

(All carbohydrates were infused at $200 \mathrm{~g} / \mathrm{h}$ for $8 \mathrm{~h}$; all solutions were infused at $21 . / \mathrm{h}$ )

\begin{tabular}{|c|c|c|c|c|c|}
\hline Infusate & $\mathrm{pH}$ & $\begin{array}{c}\text { TRS } \\
(\mathrm{mg} / 100 \mathrm{ml})\end{array}$ & $\begin{array}{c}\text { VFA } \\
(\mathrm{m}-\mathrm{moles} / 1 .)\end{array}$ & $\begin{array}{c}\text { Lactic acid } \\
(\mathrm{m} \text {-moles/1.) }\end{array}$ & Starch* \\
\hline \multicolumn{6}{|c|}{ Cow Adelaide } \\
\hline Water & +0.4 & - & $-18 \cdot 7$ & -0.4 & 0 \\
\hline Water & +0.4 & -0.4 & $-20 \cdot 4$ & $\circ$ & $-I$ \\
\hline Glucose & -0.6 & +317.4 & $+I 0 \cdot I$ & $+12 \cdot 6$ & +2 \\
\hline Glucose & -0.4 & $+4 \cdot 2$ & $+28 \cdot 8$ & +0.5 & +2 \\
\hline Glucose & -0.6 & +0.1 & $+28 \cdot 3$ & $+2 \cdot 2$ & +3 \\
\hline Fructose & -0.8 & +244.5 & $+3 \cdot 6$ & $+16 \cdot 6$ & +2 \\
\hline Galactose & -0.9 & 0 & $+31 \cdot 4$ & 0 & 0 \\
\hline Xylose & -0.6 & $+395 \cdot 3$ & $+20 \cdot I$ & $\circ$ & $+I$ \\
\hline Arabinose & -0.6 & +258.8 & +257 & +0.4 & $+I$ \\
\hline \multicolumn{6}{|c|}{ Cow Desmine } \\
\hline Water & +0.7 & - & $-23 \cdot 2$ & $\circ$ & -2 \\
\hline Water & $+0 . I$ & $+0 . I$ & $+r \cdot 3$ & 0 & $-I$ \\
\hline Glucose & -0.2 & $+31 \cdot I$ & - & -0.1 & - \\
\hline Glucose & $-0 \cdot I$ & $+11 \cdot 5$ & $+34 \cdot 0$ & +0.7 & $+I$ \\
\hline Glucose & -0.2 & +0.7 & $+18 \cdot 7$ & +0.5 & 0 \\
\hline Fructose & -0.3 & 0 & $+9 \cdot 0$ & $+3 \cdot 1$ & +2 \\
\hline Galactose & -0.1 & $+306 \cdot 9$ & $+x \times \cdot 3$ & $+x \cdot 0$ & $+x$ \\
\hline Xylose & -0.5 & +305.9 & $+16 \cdot 3$ & -0.2 & $\circ$ \\
\hline Arabinose & -0.7 & +9.4 & $+28 \cdot 9$ & 0 & $+I$ \\
\hline
\end{tabular}

* Estimated by eye on a scale of $0-3$ from the iodophilic reaction. 
in vivo and the results of substrate infusion therefore tended to be confused by the variation of the basal fermentation. The effects of this variability of the basal fermentation were clearly reflected in the metabolism of added substrates as can be seen in Tables 7 and 8 where the effects of two infusions of water and three infusions of glucose into each cow are recorded.

Table 8. In vivo: change in the molar proportions of volatile fatty acids in the rumen between the start of the infusion and the end $8 \mathrm{~h}$ later

(All carbohydrates were infused at $200 \mathrm{~g} / \mathrm{h}$ for $8 \mathrm{~h}$; all solutions were infused at $21 . / \mathrm{h}$ )

\begin{tabular}{|c|c|c|c|c|c|c|}
\hline \multirow[b]{2}{*}{ Infusate } & \multicolumn{6}{|c|}{ Molar \% } \\
\hline & Acetic & Propionic & Isobutyric & n-Butyric & Isovaleric & n-Valeric \\
\hline \multicolumn{7}{|c|}{ Cow Adelaide } \\
\hline Water & +3.4 & $-6 \cdot 1$ & +0.5 & $+1 \cdot 7$ & +0.4 & +0.1 \\
\hline Water & $+6 \cdot 7$ & $-9 \cdot I$ & $+1 \cdot 2$ & -0.5 & $+2 \cdot 3$ & -0.6 \\
\hline Glucose & $-I \cdot 2$ & +0.2 & -0.4 & $+2 \cdot I$ & -0.3 & -0.4 \\
\hline Glucose & -9.6 & $+2 \cdot 7$ & +0.3 & $+4 \cdot 2$ & +0.5 & $+I \cdot 9$ \\
\hline Glucose & $-9 \cdot 8$ & $+9 \cdot 5$ & -0.5 & $+I \cdot I$ & -0.1 & -0.2 \\
\hline Fructose & -0.4 & $-8 \cdot 2$ & +0.3 & $+8 \cdot 6$ & +0.2 & -0.5 \\
\hline Galactose & $-8 \cdot 2$ & $+17 \cdot 4$ & -0.6 & $-6 \cdot 5$ & $-1 \cdot 2$ & -0.9 \\
\hline Xylose & $-7 \cdot 2$ & $+15 \cdot 3$ & -0.5 & $-6 \cdot 5$ & -0.5 & -0.6 \\
\hline Arabinose & -0.2 & $+12 \cdot 8$ & -0.5 & -10.7 & -0.8 & -0.6 \\
\hline \multicolumn{7}{|c|}{ Cow Desmine } \\
\hline Water & $+3 \cdot 7$ & $-3 \cdot 6$ & +0.8 & $-1 \cdot 6$ & $+1 \cdot 4$ & -0.7 \\
\hline Water & $+3 \cdot 6$ & +0.3 & +0.2 & $-4 \cdot 4$ & +0.3 & $\circ$ \\
\hline Glucose & $-2 \cdot 3$ & +0.7 & +0.4 & -0.3 & +0.2 & $+I \cdot 3$ \\
\hline Glucose & $-7 \cdot 2$ & $-I \cdot O$ & +0.2 & $+8 \cdot 4$ & -0.2 & -0.2 \\
\hline Glucose & -10.6 & +0.2 & +0.2 & $+I I \cdot 2$ & -0.7 & -0.3 \\
\hline Fructose & $-5 \cdot I$ & $-4 \cdot 9$ & -0.3 & +6.5 & 0 & +3.8 \\
\hline Galactose & $+5 \cdot 6$ & $+1 \cdot 5$ & -0.3 & $-6 \cdot 1$ & +0.1 & -0.8 \\
\hline Xylose & $-5 \cdot 2$ & $+9 \cdot 0$ & $\circ$ & -3.5 & -0.2 & -0.1 \\
\hline Arabinose & $+0 \cdot 1$ & $+8 \cdot 5$ & -0.2 & $-6 \cdot 4$ & $-x \cdot 4$ & -0.6 \\
\hline
\end{tabular}

Variability between occasions in the concentration of substrate, VFA, lactic acid and starch at the end of each incubation (Table 7 ) was too great for any conclusions to be drawn regarding the amounts of the carbohydrates fermented. Changes in the proportion of VFA (Table 8), while again varying widely, did offer a clearer pattern especially when compared with the in vitro results. In all instances the infusion of galactose, xylose and arabinose caused marked increases in the proportion of propionic acid and decreases in the proportion of $n$-butyric acid in agreement with the in vitro results. Infusion of fructose resulted in a marked decrease in the proportion of propionic acid whereas infusion of glucose caused little change or an increase, again reflecting differences detected in vitro.

\section{DISCUSSION}

Suitability of the technique

The wide variability in both the basal fermentation and the fermentation of added substrate has already been emphasized. The in vivo infusions were begun $14 \mathrm{~h}$ after 
feeding when the rate of fermentation of the feed was expected to be low. When the hay diet was given infusion of water was associated with relatively large changes in the concentration of total VFA during the $8 \mathrm{~h}$ infusion but with only very small changes, usually less than one percentage unit, in the proportions of VFA (Sutton, I968). In the present experiments changes in the concentrations and proportions of VFA during the control infusion were usually not only greater but also much more variable. Thus, compared with the hay diet, a greater variability of fermentation of added substrate was superimposed on a more variable basal fermentation, considerably reducing the sensitivity of the in vivo technique. A further difficulty was that, whereas when the hay diet was given a steady state situation was approached in the rumen by the end of the $8 \mathrm{~h}$ infusion, in the present experiments changes in the concentration of VFA and carbohydrates and in the proportions of VFA continued throughout the infusion, though at a reduced rate towards the end.

The in vitro technique included its own control on each occasion. If it is assumed that the results obtained in vitro are valid, then it is clearly better suited to comparing the fermentation of different substrates than is the in vivo technique when a highly variable situation is being examined.

The validity of the in vitro technique when the hay diet was given was considered previously (Sutton, I968) and, although it was not possible to compare the results in absolute terms, qualitative agreement between the in vivo and in vitro experiments was very good. Similar comparisons in the present experiments are less easy because of the variability of the fermentation, but the results indicate a similar degree of agreement and further discussion will assume that there are no serious discrepancies in qualitative terms between results obtained by use of the two techniques.

The carbohydrate additions were not begun until $\mathrm{I} 4 \mathrm{~h}$ after feeding as, by that time, the rate of fermentation of the basal ration was approaching a minimum and it was expected that the fermentation of the added carbohydrates would be more easily measured than if the additions were made sooner after feeding (Sutton, I968). However the carbohydrates might have been fermented somewhat differently if they had been added to the rumen contents at some other time after feeding.

\section{Comparison of different carbohydrates}

As in the previous studies, in which cows were given a diet containing a much larger proportion of hay, clear differences have been found among the soluble carbohydrates in the pattern of their fermentation. No significant differences were detected between the two pentoses but all the other carbohydrates differed from one another in one respect or another. The fermentation of galactose resembled that of the pentoses; they all produced about 40\% acetic acid, 50\% propionic acid, very little $\mathrm{n}$-butyric, $\mathrm{n}$-valeric, or lactic acid and relatively small amounts of starch. However, galactose differed from the pentoses in being fermented more rapidly, the mean difference between galactose and xylose, though not arabinose, being significant $(P<0.05)$.

The other three carbohydrates, glucose, fructose and sucrose, showed features in common. Compared with galactose and the pentoses, they produced relatively greater 
proportions of n-butyric acid and, in one cow, n-valeric acid, and a smaller proportion of propionic acid. In addition they were the only carbohydrates to produce appreciable amounts of lactic acid. They differed from one another however in various details. Thus the rate of fermentation of sucrose resembled that of glucose, both sugars being fermented significantly $(P<0.05)$ faster than fructose, but the proportions of VFA produced from sucrose resembled those from fructose rather than those from glucose.

\section{Comparison of fermentation on the two diets}

The results have shown that soluble carbohydrates can be fermented at different rates and to different proportions of end-products whether the diet consists primarily of hay or of flaked maize. However differences between the two diets were apparent in the fermentation of the added carbohydrates and these have been examined in greatest detail from the results of the in vitro experiments.

Table 9. Mean amounts of carbohydrate fermented in vitro per $100 \mathrm{~g}$ rumen contents from two cows fed on hay or flaked maize diets

(The amounts of carbohydrate added/I00 $\mathrm{g}$ rumen contents during the $2 \mathrm{~h}$ incubation were $500 \mathrm{mg}$ ( $475 \mathrm{mg}$ sucrose) on the hay diet and $597 \mathrm{mg}$ ( $567 \mathrm{mg}$ sucrose) on the Haked maize diet)

\begin{tabular}{|c|c|c|c|c|}
\hline \multirow[b]{3}{*}{ Substrate } & \multicolumn{4}{|c|}{ Amount fermented (mg/roo g rumen contents) } \\
\hline & \multicolumn{2}{|c|}{ Hay diet } & \multicolumn{2}{|c|}{ Flaked maize diet } \\
\hline & Cow Adelaide & Cow Desmine & Cow Adelaide & Cow Desmine \\
\hline Sucrose & $475(I)^{*}$ & $466(\mathrm{I})$ & $48 \mathrm{r}$ & 522 \\
\hline Glucose & $497(3)$ & $498(3)$ & 465 & 561 \\
\hline Fructose & $499(2)$ & $500(2)$ & 382 & $49 \mathrm{I}$ \\
\hline Galactose & $275(2)$ & $259(2)$ & 357 & 479 \\
\hline Xylose & $262(2)$ & $234(2)$ & 299 & 393 \\
\hline Arabinose & $253(2)$ & $233(2)$ & 323 & $\begin{array}{l}393 \\
440\end{array}$ \\
\hline
\end{tabular}

* The figures in parentheses on the hay diet indicate the number of occasions on which the fermentation of each carbohydrate was examined with each cow. On the flaked maize diet, all carbohydrates were examined on three occasions with each cow.

A comparison of the results from the two series of experiments must be treated with caution in view of the small number of animals used. Both the cow $\times$ substrate interaction and differences between cows were significant in several instances on the flaked maize diet though not on the hay diet. There is no information to indicate which of the two cows yielded the more 'typical' results for cows given a large proportion of flaked maize.

The amounts of carbohydrates fermented in vitro on the two diets are shown in Table 9 in $\mathrm{mg} / \mathrm{roo} \mathrm{g}$ rumen contents. Galactose, xylose and arabinose were fermented more rapidly by both cows on the flaked maize diet than on the hay diet, but the results with the other carbohydrates were inconclusive, owing mainly to the wide differences between the cows on the flaked maize diet. Fructose was fermented less rapidly than glucose and sucrose on the flaked maize, but not on the hay diet. Sucrose, glucose and fructose were almost completely fermented on the hay diet; thus the 
availability of substrate became limiting and the results probably underestimate the potential rate of fermentation.

The molar proportions of VFA produced from the added substrates differed considerably between the two basal rations. With all the substrates the mean net production of acetic and n-butyric acids was less and that of $n$-valeric acid was more on the flaked maize than on the hay diets; the mean net production of propionic acid from fructose was the same on the two rations but from all the other substrates it was greater on the flaked maize ration. The mean differences were generally greater for galactose, xylose and arabinose than for glucose, fructose and sucrose.

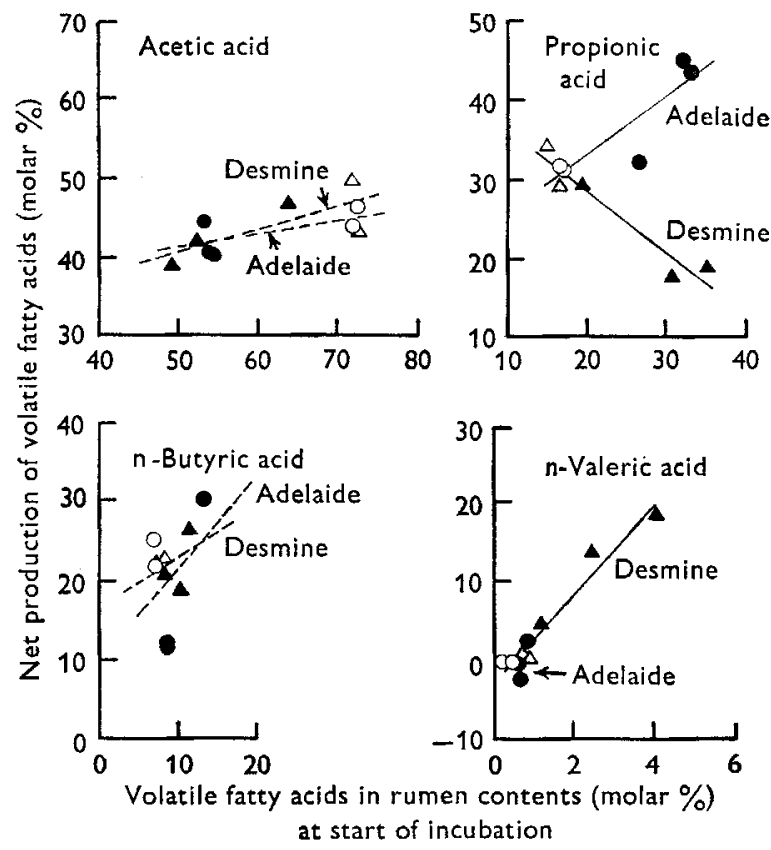

Fig. 2. Relation of the molar proportion of volatile fatty acids produced to their molar proportion in the rumen contents at the start of the incubation when fructose was incubated in vitro for $2 \mathrm{~h}$ with rumen contents from two cows fed on a hay ration $(O$, Adelaide; $\triangle$, Desmine) and a flaked maize ration (, Adelaide; $\Delta$, Desmine). Only the solid regression lines are significant $(P<0.05)$. Further details are given on p. 579.

The effects of the basal rations on the proportions of VFA produced were examined in greater detail by calculation for each carbohydrate and each cow of the regression of the molar proportion of each VFA produced on the molar proportion of that VFA in the rumen contents at the start of the incubation. In addition, the regression was calculated of the net production of each VFA per $g$ carbohydrate fermented (m-moles/g) on the concentration of each VFA in the rumen contents at the start of the incubation (m-moles $/ \mathrm{kg}$ ). Regression coefficients calculated on these two bases were generally similar in sign and degree of significance, and the results will be discussed in terms of molar proportions only.

The regressions for the monosaccharides were calculated by combining results for each occasion in Expt 3 on the hay diet (Sutton, I968) and from the present 
experiments. Regressions for sucrose were calculated from the results of Expt 4 on the hay diet and from the present experiments; the fermentation of sucrose was not examined in Expt 3 on the hay diet. Since no significant differences in the fermentation of xylose and arabinose were found in any of the experiments, the results for the pentoses were averaged.

The regressions were broadly similar for glucose, fructose and sucrose on the one hand and for galactose and the pentoses on the other. Results are shown for fructose (Fig. 2) and for galactose (Fig. 3) to illustrate the major differences between the two groups.

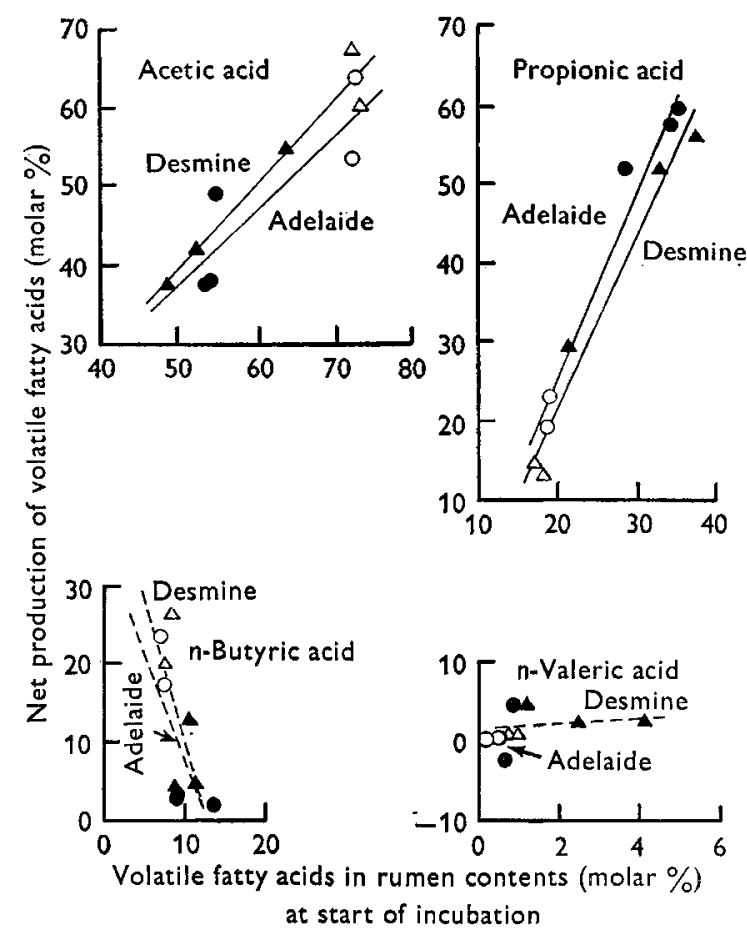

Fig. 3. Relation of the molar proportion of volatile fatty acids produced to their molar proportion in the rumen contents at the start of the incubation when galactose was incubated in vitro for $2 \mathrm{~h}$ with rumen contents from two cows fed on a hay ration ( $\bigcirc$, Adelaide; $\triangle$, Desmine) and a flaked maize ration ( $\bullet$, Adelaide; $\boldsymbol{\Delta}$, Desmine). Only the solid regression lines are significant $(P<0.05)$. Further details are given on p. 579 .

With fructose most regression coefficients were positive but only those for propionic acid with Adelaide and for $\mathrm{n}$-valeric acid with Desmine reached significance $(P<0.05)$. The significant $(P<0.05)$ negative regression for propionic acid production with Desmine reflected the relatively low proportion of propionic acid produced when a high proportion of propionic acid in the rumen at the start of the incubation was accompanied by a relatively high proportion of $n$-valeric acid. In Adelaide, where a positive regression was found, the proportion of $n$-valeric acid in the rumen remained low when the proportion of propionic acid present was high.

The regressions for sucrose were very similar to those for fructose. However, the 
regressions for glucose differed somewhat, mainly in that the regression coefficients for propionic acid production were positive for both cows although that for Desmine was smaller than that for Adelaide. Further, the regression coefficient for $n$-valeric acid production was smaller for glucose than for fructose and sucrose.

Regressions for galactose (Fig. 3) and the pentoses were very similar and differed from those for the other three sugars. The regressions for both acetic and propionic acid production were positive and significant for both cows $(P<0.05)$, except that acetic acid production from galactose for Adelaide was only significant at $P<0 \cdot 1$. No other regressions for galactose or the pentoses were significant $(P>0.05)$.

In no instance was there a significant $(P<0.05)$ regression between the proportion of n-butyric acid produced from a carbohydrate and the proportion of the acid present in the rumen at the start of the incubations.

The results show that the proportions of acetic, propionic and n-valeric acids produced from soluble carbohydrates may vary according to the relative proportions of these VFA in the rumen at the start of the incubations. However, the degree of the relationship varies markedly with different carbohydrates. Almost all significant $(P<0.05)$ regressions were positive, indicating that the proportions of end-products generally reflected the type of basal fermentation. However more complex relationships also existed. Thus a fermentation producing a relatively large proportion of n-valeric acid appeared to cause a marked fall in the proportion of propionic acid produced from fructose and sucrose but not from galactose and the pentoses.

Although lactic acid is often found in relatively high concentrations in the rumen when diets containing large amounts of cereals are fed, there were no clear differences between the diets in the amounts of lactic acid produced from the added carbohydrates. Recovery of fermented carbohydrate in VFA and lactic acid was rather higher on the flaked maize diet than on the hay diet but little meaning should be attached to the difference in view of the errors associated with the calculation of recovery.

Evidence from other sources supports the suggestion that the fermentation of soluble carbohydrates varies with the basal diet given. Sucrose, glucose and fructose have been shown to be fermented at different rates according to whether the diet consists of hay of different qualities or of grass (Quin, I943; Elsden, 1945; Thomas, 1960). Eusebio et al. (1959), Baldwin et al. (1963) and Wallnöfer et al. (1966) incubated glucose, labelled with radioactive carbon, with rumen contents from cows given various proportions of hay and concentrates. All of them found that the ratio of the labelled acetic acid to propionic acid declined markedly as the proportion of hay in the diet was reduced, and the work of Wallnöfer et al. (r966) further suggested that the pathways of propionic acid formation were also altered. McNaught (I95I) showed that different proportions of VFA were produced from maltose and pentoses according to whether the rumen contents were from a steer receiving grass or from the same steer when it was receiving hay and concentrates. Differences due to diet were also found when insoluble carbohydrates such as cellulose and hemicellulose (Satter, Suttie \& Baumgardt, 1964) were fermented by rumen contents.

Thus, there is considerable evidence that a variety of carbohydrates is metabolized to different end-products according to the type of basal fermentation. There clearly 
remains some controversy as to the extent and nature of these changes. Much of the confusion may well reflect the wide range of types of fermentation that occur in the rumen, particularly when large proportions of concentrates are given. The considerable differences found in the present studies between two cows on very similar diets and even between occasions in the same cow clearly illustrate the problems.

There are several possible causes for these differences in the fermentation of carbohydrates. In association with changes of diet, changes have been demonstrated in the microbial species (see Hungate, 1966), in enzyme patterns in the rumen contents (Baldwin \& Palmquist, 1965) and in the pathways whereby carbohydrates are fermented (Jayasuriya \& Hungate, 1959; Baldwin et al. 1963; Wallnöfer et al. 1966). Nitrogen sources and amounts (Bryant, 1965; Lewis, 1962) and carbon dioxide tension (Demeyer \& Henderickx, 1967; Satter, Suttie \& Baumgardt, 1967) have also been shown to affect the fermentation of carbohydrates.

\section{Conclusions}

This series of experiments, in delineating some of the causes and extent of variation possible in the fermentation of soluble carbohydrates in the rumen, has illustrated two major factors contributing to the difficulty experienced by those who attempt to predict the proportions of VFA which will be found in the rumen when a particular diet is given to cows. These are that widely different proportions of VFA can be produced, first, from different substrates, even though these may be closely related chemically and, second, from the same substrate under different conditions. The experiments have shown the considerable influence of dietary changes on the pattern of fermentation of simple substrates and, probably more important, the existence of an overall relationship between the proportions of three of the four major acids present in the rumen and the proportions of these acids produced when soluble carbohydrates are added.

I am most grateful to Dr C. C. Balch for his advice and encouragement throughout this work and to Mr D. R. Westgarth for his assistance with many of the statistical analyses. I thank Dr A. T. Cowie for establishing the rumen fistulas, Mr V. W. Johnson for care of the experimental animals, and Mr E. Schuller and Mr K. M. T. Hearne for their skilled technical assistance. The work was supported in part by a generous grant from the Sugar Research Foundation Inc., New York.

\section{REFERENCES}

Balch, C. C. \& Cowie, A. T. (1962). Cornell Vet. 52, 206.

Baldwin, R. L. \& Palmquist, D. L. (1965). Appl. Microbiol. 13, 194.

Baldwin, R. L., Wood, W. A. \& Emery, R. S. (1963). F. Bact. 85, 1346.

Bryant, A. M. (1965). N.Z. भl agric. Res. 8, 118.

Demeyer, D. I. \& Henderickx, H. K. (1967). Biochem. F. ro5, 271.

Elsden, S. R. (1945). F. exp. Biol. 22, 5 I.

Elsden, S. R. \& Gibson, Q. H. (1954). Biochem. F. 58, I 54.

Eusebio, A. N., Shaw, J. C., Leffel, E. C., Lakshmanan, S. \& Doetsch, R. N. (1959). F. Dairy Sci. 42, 692 .

Hungate, R. E. (1966). The Rumen and its Microbes. London: Academic Press Inc. 
Jayasuriya, G. C. N. \& Hungate, R. E. (1959). Archs Biochem. Biophys. 82, 274. Lewis, D. (1962). F. agric. Sci., Camb. 58, 73 .

McDougall, E. I. (1948). Biochem. F. 43, 99.

McNaught, M. L. (195I). Biochem. F. 49, 325.

Phillipson, A. T. \& McAnally, R. A. (1942). F. exp. Biol. 19, 199.

Quin, J. I. (I943). Onderstepoort F. vet. Sci. 18, 9т.

Satter, L. D., Suttie, J. W. \& Baumgardt, B. R. (rg64). F. Dairy Sci. 47, 1365.

Satter, L. D., Suttie, J. W. \& Baumgardt, B. R. (1967). F. Dairy Sci. 50, 1626.

Sutton, J. D. (1968). Br. F. Nutr. 21, 689.

Thomas, G. J. (1960). F. agric. Sci., Camb. 54, 360.

Wailnöfer, P., Baldwin, R. L. \& Stagno, E. (1966). Appl. Microbiol. 14, 1004. 